\title{
Proposed reforms delay Quebec's Bill 20
}

$\mathrm{Q}$ uebec family doctors reached a last-minute deal with the provincial government, averting some far-reaching consequences of Bill 20 at least until 2018.

Under the deal, quotas requiring doctors to take on more patients or face penalties of up to $30 \%$ of their income have been put on hold. In exchange, family physicians have guaranteed that $85 \%$ of Quebec's population will have access to a family doctor by Dec. 31, 2017.

"And if that target is met - and we are very confident that it can be done - Bill 20 will be repealed by the National Assembly, says Dr. Louis Godin, head of the Fédération des médecins omnipraticiens du Québec. "So we're satisfied, it's in line with the proposals we put forth before a parliamentary commission in March."

The deal, which was reached on May 25, allows the province's 8800 family doctors flexibility in terms of finding ways to see more patients. One seismic shift being considered is a move to decrease the number of hours worked in hospitals and increase the work in clinics or doctors' offices. This would be gradually phased in.

Over the last 15-20 years, Godin says, doctors in Quebec have increasingly worked in hospitals. Doctors are required to work 12 hours a week in hospitals, but routinely put in three or four days as they attempt to follow their patients' care. Hospitals went along willingly.

The result, says Godin, is that family doctors in Quebec spend 30\%-40\% of their time in hospitals compared to $20 \%$ for doctors in Ontario.

Godin anticipates "a freeze" of family doctors in hospitals. "Those who are there can stay there and those who leave the hospital setting will be replaced, but we will not add other doctors beyond that unless there is a need related to family medicine."

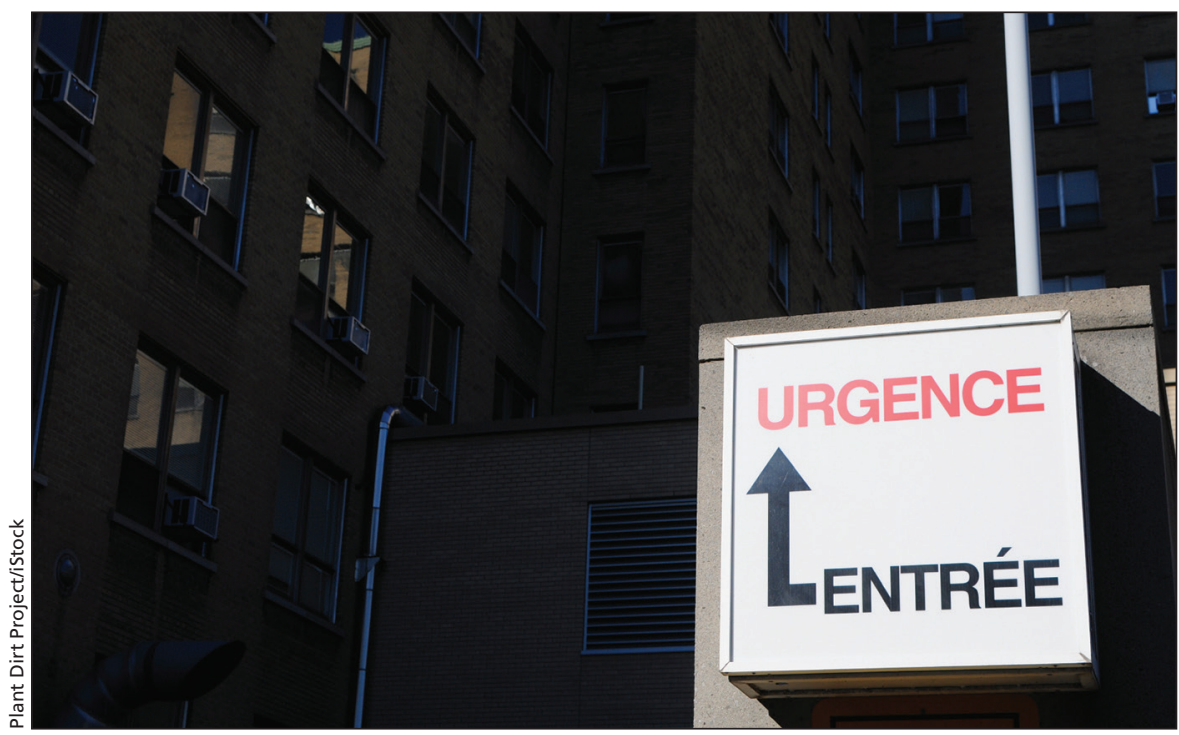

Physicians may be working fewer hours in hospitals and more in the community under a proposed reform.

And with some 500 new doctors every year, there is the ability to gradually increase the number of family physicians in doctors' offices, he says.

"One thing is for sure: we will not do what has been done over the last years, that is, to add $40 \%$ more doctors every year in hospitals."

Over time, it's expected that specialists will take over some of family physicians' workload in hospitals. Specialists are currently trying to negotiate a separate agreement with the Quebec minister of health to mitigate the effects of Bill 20. It stipulates, among other things, that specialists respond to $75 \%$ of referrals in hospital emergency units within four hours or face financial penalties.

Access to family doctors needs to improve, says Dr. Maxine Dumas Pilon, president of the Collège québécois des médecins de famille. Today, a patient who cuts his finger and doesn't have a family doctor goes to the hospital and adds to long lineups, she says.

Reaching the goal of providing a doctor for $85 \%$ of Quebec's population by 2017 means changes in the day-to- day practice of family physicians, Dumas Pilon says. To be more efficient, doctors will need more services in their offices, such as electronic access to medical files.

There is also talk about revisiting the idea of routine annual medical exams for all patients. Reducing the length of the exam or eliminating it altogether for a 30-year-old healthy male "would free up some time for less stable patients," says Dumas Pilon.

One thing that is "absolutely not" on the table, though, is time-limited doctors' appointments so that more patients can be seen in a day, insists Godin. For now, doctors no longer fear that they'll come under the direct supervision of the Ministry of Health and the minister himself. Patient quotas had been established by tables set by the department.

"But let's face it," concludes Dumas Pilon, "if we don't succeed, the supervision aspect will come back so, clearly, we have a sword hanging over our head." - Huguette Young, Ottawa, Ont.

CMAJ 2015. DOI:10.1503/cmaj.109-5086 